Celso Arango

Olalla Robles

Mara Parellada

David Fraguas

Ana Ruiz-Sancho

Oscar Medina

Arantzazu Zabala

Igor Bombín

Dolores Moreno

\section{Olanzapine compared to quetiapine in adolescents with a first psychotic episode}

Received: 29 March 2008

Accepted: 9 December 2008

Published online: 5 February 2009

Clinical Trials Registry:

Trial Registry name: Estudio piloto comparativo de quetiapina frente a olanzapina en pacientes con primeros brotes psicóticos de inicio en la infancia y la adolescencia.

URL: http://www.agemed.es/

Registration identification number: 02-0300, SPGM-001.

C. Arango, $\mathrm{MD}, \mathrm{PhD}(\triangle) \cdot$ O. Robles, $\mathrm{PhD}$

M. Parellada, MD, $\mathrm{PhD}$

A. Ruiz-Sancho, MD - O. Medina, MD

A. Zabala, $\mathrm{PhD} \cdot \mathrm{D}$. Moreno, $\mathrm{MD}, \mathrm{PhD}$

Psychiatry Department, Adolescent Unit

Hospital General Universitario Gregorio

Marañón

Centro de Investigación Biomédica

en Red de Salud Mental, CIBERSAM

C/Ibiza 43, 28009 Madrid, Spain

Tel. + 34-91/5868133

Fax: +34-91/4265108

E-Mail: carango@mce.hggm.es

D. Fraguas, MD

Department of Psychiatry

Hospital Infanta Sofia

San Sebastian de los Reyes

Madrid, Spain

I. Bombín, $\mathrm{PhD}$

Neurological Rehabilitation Center

Oviedo, Spain
Abstract Objective To compare the efficacy, safety, and tolerability of olanzapine and quetiapine in adolescents with first episode psychosis. Method Fifty adolescents (age $16 \pm 1.25$ ) with a first episode of psychosis were randomized to quetiapine or olanzapine in a 6-month open label study. Efficacy and side effect scales, as well as vital signs and laboratory data were recorded at baseline, 7, 15, 30, 90, and 180 days (end of study). Results Out of the total sample included in the study, 32 patients completed the trial (quetiapine $n=16$, olanzapine $n=16$ ). Patients in both treatment groups had a significant reduction in all clinical scales with the exception of the negative scale of the Positive and Negative Symptom Scale (PANSS) for olanzapine and the general psychopathology scale of the PANSS for quetiapine. The only difference between treatment arms on the clinical scales was observed on the patients' strength and difficulties questionnaire (SDQ) scale, with greater improvement for olanzapine. Patients on olanzapine gained $15.5 \mathrm{~kg}$ and patients on quetiapine gained $5.5 \mathrm{~kg}$. Conclusion Olanzapine and quetiapine reduced psychotic symptoms in this adolescent sample. Patients on olanzapine gained significantly more weight. Side effects with both drugs seemed to be more prevalent than those reported in adult studies.

Key words olanzapine quetiapine - safety tolerability - adolescent first episode psychosis

\section{Introduction}

There has been a drastic increase in the prescription of antipsychotics in children and adolescents in recent years [32]. Nevertheless, there is very limited efficacy or safety evidence from randomized controlled trials to support these prescribing trends in children and adolescents with psychotic symptoms [5]. In fact, there have been more studies with SGA for the treatment of disruptive behaviors and developmental disorders than in patients with psychotic 
symptoms [8]. To our knowledge, only three doubleblind studies have compared the efficacy of different antipsychotics. Moreover, two of these studies were performed with a very low prevalence entity: treatment resistant patients with childhood-onset schizophrenia [21, 37]. Kumra et al. [21] found that clozapine was superior to haloperidol in the treatment of 21 treatment resistant patients with prepubertalonset schizophrenia. In a more recent study, clozapine was significantly superior to olanzapine only for the treatment of negative symptoms [37]. In the only other double-blind randomized study, Sikich et al. [38] studied 50 patients with psychotic symptoms, with a mean length of illness of 2.4 years. Haloperidol, olanzapine, and risperidone showed similar efficacy in symptom reduction. In this study, weight gain and extrapyramidal effects appeared more prevalent and severe than reported in adults. Most studies are short term, usually lasting 6-8 weeks $[37,38]$. We are not aware of any previous randomized controlled trial with two SGAs in first episode psychosis in adolescence.

This study was designed to provide prospective, randomized information at 6 months about the efficacy and safety of two-second generation antipsychotics widely prescribed in pediatric populations. Based on previous studies in adult first episode psychosis and studies on tolerability in pediatric populations, we hypothesized that there would not be a difference between quetiapine and olanzapine in terms of symptom reduction, and that side effects would be very prevalent in this population and different for the two antipsychotics.

\section{Methods}

\section{Study design}

This is a 6-month, comparative, randomized (quetiapine vs. olanzapine), open label, parallel group study in adolescent patients with first episode psychosis. In this article, we report on clinical efficacy, tolerability, and safety of antipsychotic drug treatment. However, the primary outcome for this trial was cognitive efficacy. Results for cognitive outcome are reported elsewhere (Robles et al., submitted). Therefore, here we focus on the clinical secondary variables.

\section{Subjects}

Fifty patients consecutively admitted to the Adolescent Unit of Hospital General Universitario "Gregorio Marañón" (Madrid, Spain) with a diagnosis of psychosis (i.e., schizophrenia or any other psychotic disorder according to DSM-IV criteria) were invited to participate in the study. All patients had a first episode of psychosis before the age of 18 , lasting less than 1 year after onset of the first positive symptom (mean duration of delusions $0.3 \pm 0.3$ years; hallucinations $0.4 \pm 0.5$ years). Adolescents were 12-18 years of age.

Diagnostic information was collected at baseline by means of the Kiddie-SADS-Present and Lifetime Version (K-SADS-PL). A clinical psychiatrist with formal training in the K-SADS-PL interviewed participants and administered diagnostic, psychiatric, safety, and tolerability scales over the six research visits (see "Outcome measures" for scales and frequency). The Internal Review Board (IRB) approved all procedures, including recruitment and consent. Written informed consent was obtained from participants and their parents or legal guardians prior to enrollment in the study.

We excluded subjects if the psychotic symptoms appeared to result from acute intoxication or withdrawal (if psychotic symptoms did not persist after 14 days of a negative urine drug screening), if they met DSM-IV criteria for any substance abuse, mental retardation, or pervasive developmental disorder, suffered from any organic central nervous system disorder, had a history of traumatic brain injury with loss of consciousness, were pregnant or breast-feeding, or were taking olanzapine or quetiapine before enrolment. Use of other antipsychotic drugs other than olanzapine or quetiapine before enrolment was allowed.

Patients were diagnosed again at 6 months by the patient's attending psychiatrist, according to DSM-IV criteria. The final sample included 17 patients with schizophrenia, 13 patients with bipolar disorder, and 20 patients with "other" psychotic disorders. Specific diagnoses at 6 months for patients included in the two treatment arms are provided in Table 1. Figure 1 provides a detailed explanation of the flow of participants throughout the trial.

\section{Randomization}

Adolescents were randomized to one of two treatment groups (quetiapine or olanzapine). Stratified random sampling was conducted according to two participant characteristics: age and gender.

\section{Medication}

Four patients randomized to quetiapine and eight patients randomized to olanzapine had previously received antipsychotics $(16.7 \%$ of the quetiapine group and $30.8 \%$ of the olanzapine group). All patients were prescribed risperidone 2-6 mg (flexible 
Table 1 Socio-demographic and clinical characteristics

\begin{tabular}{|c|c|c|c|c|c|c|c|c|c|c|c|}
\hline \multirow[t]{2}{*}{ Variables } & \multicolumn{5}{|c|}{ Quetiapine } & \multicolumn{3}{|c|}{ Olanzapine } & \multicolumn{3}{|l|}{ Analysis } \\
\hline & $n$ & Mean & & SD & & $n$ & Mean & SD & Statistic & $d f^{d}$ & $P$ \\
\hline Age $\left(\right.$ years) ${ }^{\mathrm{a}}$ & 24 & 16.3 & & 1.1 & & 26 & 15.7 & 1.4 & $U$ & - & 0.132 \\
\hline \multirow[t]{2}{*}{ Parental years of education ${ }^{a}$} & 21 & 10.6 & & 3.5 & & 15 & 9.4 & 3.8 & $U$ & - & 0.736 \\
\hline & & & $n$ & & $\%^{e}$ & & $n$ & $\%^{\mathrm{e}}$ & Statistic & $d f$ & $P$ \\
\hline Gender $^{b}$ & & & & & & & & & $\gamma^{2}$ & 1 & 0.848 \\
\hline Male & & & 19 & & 79.2 & & 20 & 76 & & & \\
\hline Female & & & 5 & & 20.8 & & 6 & 24 & & & \\
\hline Race or ethnic group ${ }^{c}$ & & & & & & & & & $\chi^{2}$ & 3 & 0.030 \\
\hline Caucasian & & & 21 & & 87.5 & & 20 & 76.9 & & & \\
\hline Caribbean Black & & & 2 & & 8.3 & & 0 & 0 & & & \\
\hline Hispanic & & & 0 & & 0.0 & & 6 & 23.1 & & & \\
\hline Gipsy & & & 1 & & 4.2 & & 0 & 0 & & & \\
\hline Parental socioeconomic status & gshe & $c h)^{b}$ & 8 & & 100.0 & & 9 & 100 & $\chi^{2}$ & 2 & 0.667 \\
\hline I & & & 0 & & 0.0 & & 0 & 0 & & & \\
\hline ॥ & & & 0 & & 0.0 & & 0 & 0 & & & \\
\hline III & & & 2 & & 25.0 & & 4 & 44.4 & & & \\
\hline IV & & & 3 & & 37.5 & & 2 & 22.2 & & & \\
\hline \multirow[t]{2}{*}{ V } & & & 3 & & 37.5 & & 3 & 33.3 & & & \\
\hline & & & $n$ & $\%^{\mathrm{e}}$ & & & $n$ & $\%{ }^{\mathrm{e}}$ & Statistic & $d f$ & $P$ \\
\hline DSM-IV diagnosis ${ }^{b}$ & & & & & & & & & $\chi^{2}$ & 2 & 0.425 \\
\hline Schizophrenia & & & 8 & 33 & & & 9 & 34.6 & & & \\
\hline Bipolar disorder & & & 8 & 33 & & & 5 & 19.2 & & & \\
\hline Other psychoses & & & 8 & 33 & & & 12 & 46.2 & & & \\
\hline Psychosis NOS & & & 2 & 25 & & & 4 & 33.3 & & & \\
\hline Schizoaffective disorder & & & 2 & 25 & & & 3 & 25 & & & \\
\hline Schizophreniform disorder & & & 2 & 25 & & & 2 & 16.6 & & & \\
\hline Major depressive episode wit & lotic & & 2 & 25 & & & 3 & 25 & & & \\
\hline
\end{tabular}

NOS not otherwise specified

${ }^{a}$ No significant differences were observed between the two treatment groups (Mann-Whitney $U ; P>0.05$ )

${ }^{\mathrm{b}}$ No significant differences were observed between the two treatment groups (Chi-square; $P>0.05$ )

'Significant differences were observed between the two treatment groups (Chi-square; $P<0.05$ )

dNot applicable when using the Mann-Whitney $U$ test

Percentage calculated according to the total randomized sample (quetiapine $n=24$, olanzapine $n=26$ )

dose at the discretion of the clinician), between 3 and 5 days prior to randomization. For patients that were not on antipsychotic treatment before, we needed between 3 and 5 days to have the informed consent explained to patients and legal representatives and have it signed. The IRB from our hospital did not allow having patients off medication before randomization. 25 patients were antipsychotic naïve prior to inclusion in the study (quetiapine: $n=15$; olanzapine: $n=10$ ). In addition we thought that the use of the same antipsychotic before randomization would reduce the heterogeneity of carrying over effects from previous different antipsychotics. Antipsychotics, other than the study drugs, were not permitted throughout the clinical trial.

Adolescents were randomized to one of two treatment groups: quetiapine $(n=24)$ or olanzapine $(n=26)$. The dose administered was determined at the discretion of the clinician. Adjunctive medications other than different antipsychotics were allowed during the clinical trial.

\section{Outcome measures}

\section{Efficacy measures}

Clinical evaluations were performed by one of the four adolescent psychiatrists participating in the research study. The primary outcome measure for symptom reduction was the Positive and Negative Symptoms Scale (PANSS) [18] Secondary clinical outcome measures were: the Global Assessment Scale for Children (C-GAS) [35], Clinical Global Impression-Severity score (CGI-S) [14], Hamilton Depression Rating Scale (HDRS-21) [15], and the Young Rating Mania Scale (YRMS) [42]. The strengths and difficulties questionnaire (SDQ) $[11,12]$ for children and adolescents was also administered. This pediatric scales provide not 
Fig. 1 Subject flowchart

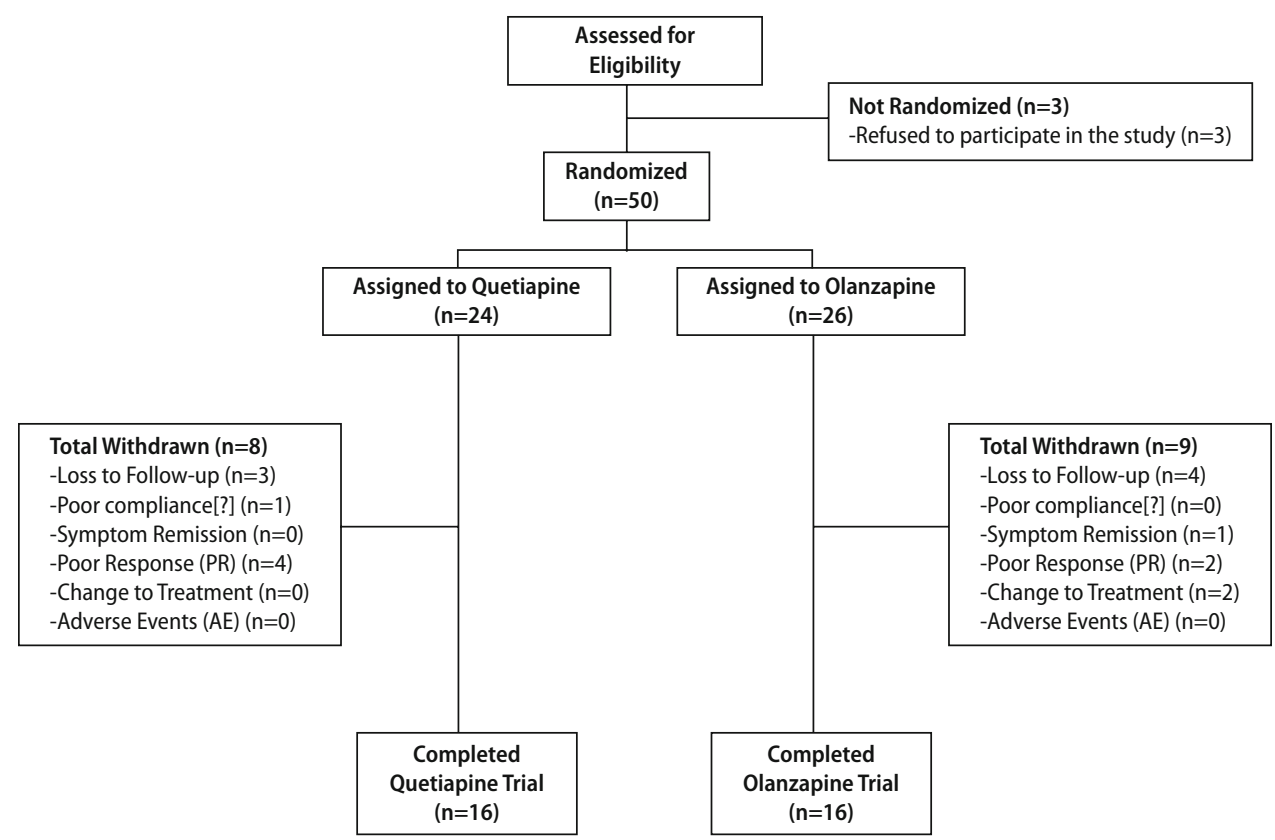

only third party and self-rated information (it has a parent, teacher and self-rated versions), but also provide important information in addition to psychopathology (behavioral, emotional, and social). All scales were administered at baseline, visit 1 (day 7), visit 2 (day 15), visit 3 (day 30), visit 4 (day 90), and visit 5 (day 180 ), except for the SDQ scale (in its three versions), which was administered only at baseline and end of study. All scales were administered by four board-certified psychiatrists with clinical experience with children and adolescents. Intraclass correlation coefficients for the four psychiatrists ranged from 0.72 to 0.96 for the total and PANSS positive, negative, and general psychopathology subscores.

\section{Measures of safety and tolerability}

Primary outcome measures for safety and tolerability were: weight changes (measured as increase in kilograms and body mass index (BMI)), UKU scale of adverse reactions [25], Barnes Akathisia Scale [2], and Simpson Neurological Rating Scale for extrapyramidal side effects [39]. All safety and tolerability scales were administered visit-wise. Blood cell counts, electrolytes, renal function, liver function, energy metabolism (glucose, HgbA1c, lipid profile), prolactin, and EKG were performed at baseline and at each visit. All blood tests were performed in a fasting state.

\section{Data analysis/statistical methods}

Descriptive statistics were obtained on demographic and outcome variables, using means with standard deviations for continuous variables and frequency distributions for categorical variables. Differences in qualitatively measures between groups were compared by means of Chi-square. Efficacy, safety, and tolerability measures were assessed using the MannWhitney $U$ nonparametric test to compare quetiapine versus olanzapine at baseline and 6 months, and the Wilcoxon nonparametric test to examine changes between baseline and 6 months within treatment arms. An intent-to-treat efficacy analysis was performed for all patients who fulfilled the inclusion criteria, with the last observation carried forward (LOCF) for any patient not completing the study. Cases in which no data was obtained after baseline were eliminated. All statistical tests were two tailed; alpha (level of significance) was $5 \%$.

The SPSS 12.0.1 statistical package was used for all analyses.

\section{Results}

\section{Subjects}

Demographic variables for subjects participating in the study are presented in Table 1 . The treatment groups were comparable in age, gender, time elapsed since onset of the first psychotic symptom, parental education, and family socioeconomic status. There was a higher proportion of Hispanic patients in the olanzapine group (Chi-square; $P<0.05$ ). With respect to baseline symptomatology, adolescents in the olanzapine group scored worse on the general psychopathology scale $(U=179.00, P=0.027)$ and total score $(U=162.00$, 
$P=0.010)$ of the PANSS. No differences were observed for the positive $(U=245.00, P=0.192)$ or negative ( $U=214.00, P=0.057)$ scales. All patients were single and lived with parents or guardians.

\section{Medication}

Mean doses at 6 months were $532.8 \pm 459.6 \mathrm{mg} /$ day of quetiapine and $9.7 \pm 6.5 \mathrm{mg} /$ day of olanzapine. Mean doses administered for each of the two drugs at the different assessment points can be seen in Table 2. There were no differences in mean treatment time between groups, with $143.75 \pm 68$ days for quetiapine and $144.1 \pm$ 62.5 for the olanzapine group. Concomitant medications during the study are provided in Table 3 . There was no difference between groups with regard to the use of any adjunctive medication at baseline or end of study.

\section{Symptom reduction}

\section{Change from baseline within treatment groups}

Decreases in PANSS total score and PANSS subscales were observed in the two treatment groups. Statisti-

Table 2 Quetiapine and olanzapine doses (mg/day) administered visit-wise

\begin{tabular}{llllll}
\hline Visit & \multicolumn{2}{l}{ Quetiapine } & & \multicolumn{2}{c}{ Olanzapine } \\
\cline { 2 - 3 } & Mean & SD & & Mean & SD \\
\hline Visit 0 (baseline) & 116.67 & 95.46 & 7.60 & 2.50 \\
Visit 1 (day 7) & 406.25 & 259.73 & & 13.37 & 5.74 \\
Visit 2 (day 15) & 552.50 & 395.05 & & 14.81 & 6.71 \\
Visit 3 (day 30) & 618.48 & 423.45 & & 15.96 & 8.10 \\
Visit 4 (day 90) & 406.25 & 200.78 & & 11.25 & 7.57 \\
Visit 5 (day 180) & 532.81 & 459.59 & & 9.71 & 6.55 \\
\hline
\end{tabular}

Table 3 Adjunctive pharmacological treatments during participation in the study

\begin{tabular}{llrlrr}
\hline \multirow{2}{*}{ Quetiapine } & \multicolumn{3}{l}{ Olanzapine } & & \\
& $n$ & $\%^{\mathrm{b}}$ & & & $\%^{\mathrm{b}}$ \\
\hline Total patients with adjunctive treatment ${ }^{\mathrm{a}}$ & 21 & 87.5 & & 21 & 80.8 \\
Anticholinergics & 3 & 12.5 & 8 & 30.8 \\
Beta-blockers & 2 & 8.3 & 1 & 3.8 \\
Benzodiazepines & 14 & 58.3 & 17 & 65.4 \\
Antidepressants & 8 & 33.3 & 10 & 38.5 \\
Antiepileptics & 7 & 29.2 & 7 & 26.9 \\
Lithium & 6 & 25.0 & 2 & 7.7 \\
Analgesics & 2 & 8.3 & 0 & 0.0 \\
Iron compounds & 1 & 4.2 & 0 & 0.0 \\
Non-steroidal anti-inflammatory drugs & 1 & 4.2 & 0 & 0.0 \\
Cough medications & 1 & 4.2 & 0 & 0.0 \\
\hline
\end{tabular}

${ }^{a}$ There were no significant differences between the two treatment groups (Chisquare; $P>0.05$ )

${ }^{b}$ Percentage calculated according to the total sample (quetiapine $n=24$, olanzapine $n=26$ ) cally significant decreases between baseline and 6 month assessments were observed in the PANSS total score $(W=-2.201, P=0.028$, and $W=-2.197$, $P=0.028$ for olanzapine and quetiapine groups, respectively), with the end point total score equal to $32.3 \%$ of the baseline score in the olanzapine group and $26 \%$ of the baseline score in the quetiapine group. The PANSS positive subscale score was significantly decreased in the two treatment groups $(W=-2.366$, $P=0.018$; and $W=-2.028, P=0.043$, for olanzapine and quetiapine groups, respectively). On percentages, these reductions were $46.4 \%$ for olanzapine, and $35.2 \%$ for quetiapine group. On the PANSS negative subscale, significant decreases were observed only for the quetiapine group (olanzapine: $W=-2.533$, $P=0.833$; quetiapine $W=-2.533, P=0.011)$. Percentages of reduction were: $16.5 \%$ in the olanzapine group, and $25.6 \%$ in the quetiapine group. On the other hand, a significant decrease was observed on the PANSS general psychopathology subscale in the olanzapine group $(W=-2.201, P=0.028)$, but not the quetiapine group $(W=-2.201, P=0.063)$. On percentages, PANSS general psychopathology subscale scores, diminished a $33.2 \%$ in the olanzapine group, and a $25 \%$ in the quetiapine group.

See Figs. 2 and 3 and changes in PANSS positive and PANSS negative scores during the trial.

The HDRS-21, YMRS, and CGI-S scores were all significantly decreased in both treatment groups. The C-GAS scores also significantly improved in the two treatment groups (Table 4).

The SDQ patient subscore was significantly decreased in patients treated with olanzapine ( $W=-2.675, P=0.007)$, but not in those treated with quetiapine ( $W=-0.534, P=0.593)$. The other SDQ subscales (parent and teacher subscores) were significantly decreased in both treatment groups (Table 4).

\section{Comparison of treatment groups}

Between-group comparisons of improvement on all the symptomatic scales failed to detect statistical differences (Table 4) with the exception of the SDQ subscale for patients $(U=122.500, P=0.026)$ in favor of olanzapine.

\section{Safety measures}

Spontaneous adverse events (i.e. other side effects than assessed by means of UKU) were reported for nine patients in the study: six patients on quetiapine and three patients on olanzapine. Only one of the reported adverse events was considered serious: physical aggression towards others, committed by a 
Fig. 2 PANSS negative subscale scores over time by treatment group

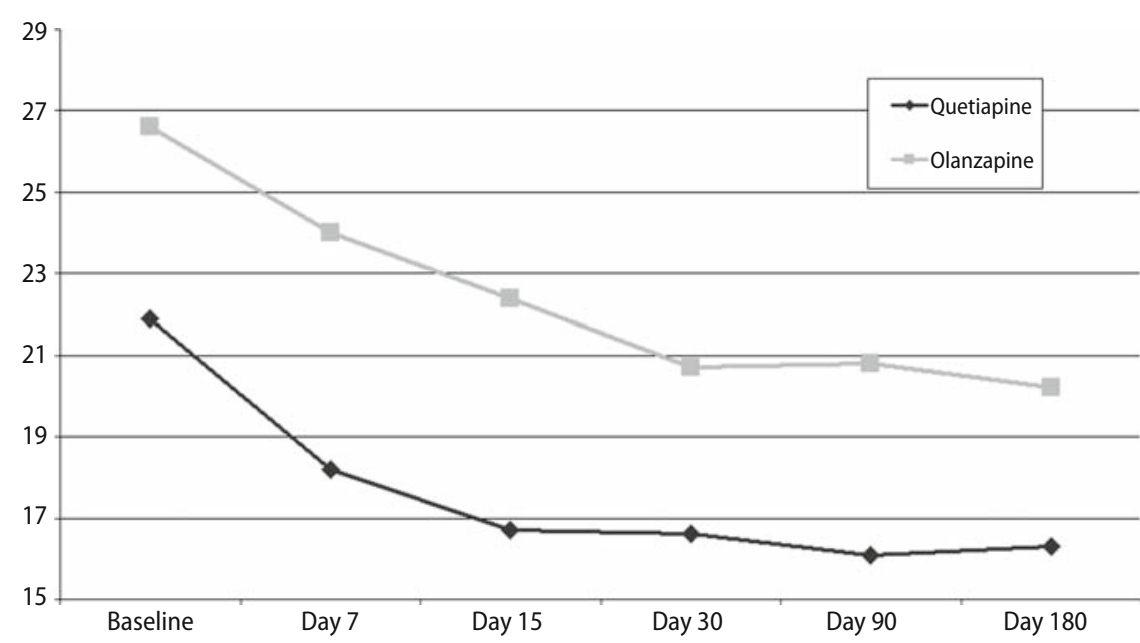

Fig. 3 PANSS positive subscale scores over time by treatment group

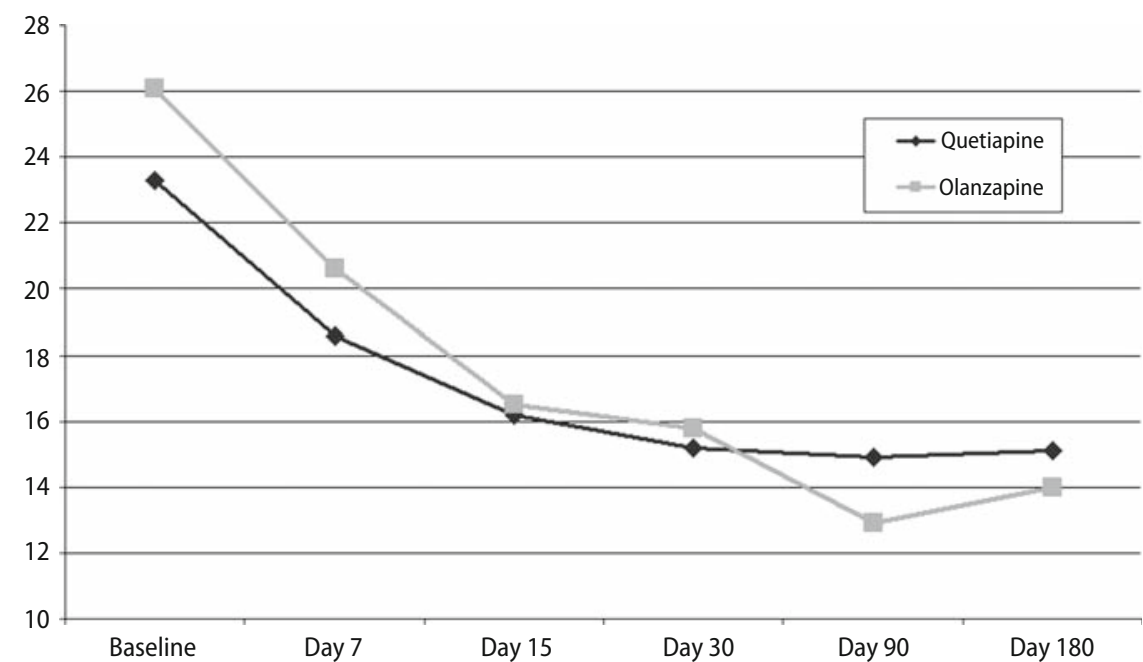

patient on quetiapine. The adverse event was considered unrelated to medication. Three patients experienced adverse events considered of moderate intensity: polyarthritis (patient on quetiapine), wrist fracture (patient on olanzapine), and muscle contracture (patient on quetiapine). All other adverse events were mild in intensity. None of the drop-outs from the study were due to an adverse event.

\section{Change from baseline within treatment groups}

Table 5 shows data on subjective side effect symptoms, as measured with the UKU, that were present at least in a $20 \%$ of patients at any time during the study with either of the two drugs.

Significant weight gain was observed in both groups (olanzapine: $15.5 \mathrm{~kg}, W=-3.621, P<0.001$; quetiapine: $5.4 \mathrm{~kg}, W=-2.899, P=0.004)$. Weight gain was disproportionate to increase in height, with
BMI increases also significant for both groups (olanzapine baseline 21.7, end of study 27.1, $W=-3.181$, $P=0.001$; quetiapine baseline 21.5 , end of study 23.3, $W=-2.919, P=0.004)$.

The effect of each treatment on various safety parameters is summarized in Table 5 .

There were no significant within-group changes with either of the two antipsychotics in systolic or diastolic blood pressure, heart rate, or QTc. There were no differences in electrolytes, liver function, renal function, energy metabolism (glucose, HgbAlc, lipid profile), or hemogram (hematite, hematocrit) parameters in either of the two groups. With respect to cholesterol levels, an increase was observed in HDL for the quetiapine group $(W=-2.670, P=0.008)$, and an increase in total cholesterol for both quetiapine $(W=-2.638, \quad P=0.008)$ and olanzapine $(W=-2.379, P=0.017)$. A decrease in the thyroid hormone T4 was observed for the quetiapine group 


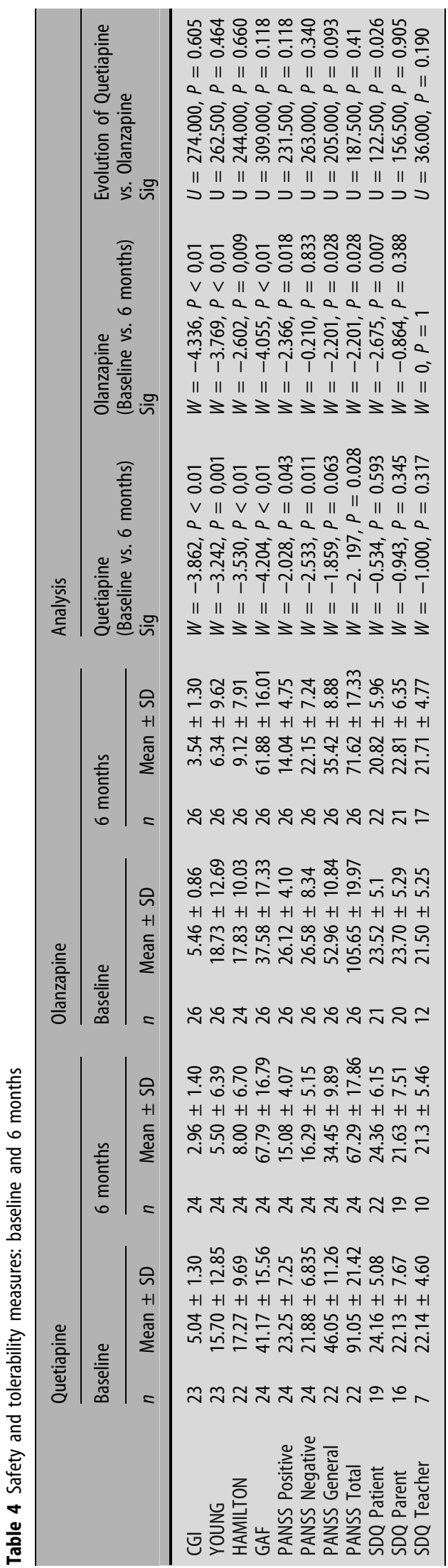

( $W=-2.226, P=0.026)$, but not for the olanzapine group $(W=-1.485, P=0.138)$.

\section{Comparison of treatment groups}

There were no significant between-group differences in the changes in prevalence of UKU items with the exception of rigidity (Mann-Whitney, $P<0.05$ ). Rigidity was more frequently present in patients treated with olanzapine.

Patients on olanzapine gained more weight $(U=34.500, P<0.001)$ and had a greater increase in BMI $(U=49.000, P=0.015)$ than patients treated with quetiapine (Table 5; Fig. 4).

There were no between-group differences in any of the cardiac, liver function, renal function, energy metabolism (glucose, HgbA1c, lipid profile), hemogram, or thyroid parameters. The HDL increase was more prominent in patients on quetiapine than in patients on olanzapine $(U=31.000, P=0.019)$.

\section{Discussion}

Adolescent patients treated with both olanzapine and quetiapine had a reduction in symptomatology over a 6-month period. The drugs had different side effect profiles. No significant differences were observed between the two treatment arms at the 6-month evaluation in terms of clinical reduction in symptoms, with patients in both arms experiencing significant clinical improvements, with the exception in one of the SDQ scores. Patients receiving olanzapine rated themselves as having improved more in terms of behaviour than patients receiving quetiapine. This difference was not supported by the parent and teacher versions of the scale, which showed significant improvements with either of the two antipsychotics. This result is in line with some previous studies reporting a better subjective feeling with olanzapine than with other second generation antipsychotics such as clozapine or risperidone $[24,31]$, although results are controversial (see, among others, $[19,40,41]$ ), and this result could also well manifest a Type I error. To our knowledge, no formal comparative studies have been carried out on subjective feelings of adolescents taking antipsychotics, and this is an area that definitely needs more research, as subjective feelings have been related to medication compliance, quality of life, and functional outcome [6, 30,31].

Both groups showed significant reduction in both total psychopathology and positive symptoms. However, a reduction in negative symptoms was observed only for patients on quetiapine, whereas a reduction in general psychopathology was significant only for 
Table 5 Side effects as measured with the UKU

\begin{tabular}{|c|c|c|c|c|}
\hline \multirow[t]{3}{*}{ Subjective side effect } & \multirow{2}{*}{\multicolumn{2}{|c|}{$\begin{array}{l}\text { Quetiapine } \\
(n=24) \\
n(\%)\end{array}$}} & \multirow{2}{*}{\multicolumn{2}{|c|}{$\begin{array}{l}\begin{array}{l}\text { Olanzapine } \\
(n=26)\end{array} \\
n(\%)\end{array}$}} \\
\hline & & & & \\
\hline & Ever & End point & Ever & End point \\
\hline Concentration difficulties & $16(67)$ & $6(37)$ & $18(72)$ & $9(56)$ \\
\hline $\begin{array}{l}\text { Asthenia/lassitude/increased } \\
\text { fatigability }\end{array}$ & $19(79)$ & $9(56)$ & $19(73)$ & $9(53)$ \\
\hline Sleepiness/sedation & $19(79)$ & $11(69)$ & $21(84)$ & $12(71)$ \\
\hline Failing memory & $14(58)$ & $4(25)$ & $12(52)$ & $7(41)$ \\
\hline Depression & $9(37)$ & $8(50)$ & $11(44)$ & $8(47)$ \\
\hline Tension/inner unrest & $15(62)$ & 7 (44) & $13(54)$ & $5(29)$ \\
\hline Increased duration of sleep & $11(46)$ & $6(37)$ & $12(48)$ & $6(35)$ \\
\hline Reduced duration of sleep & $4(17)$ & $0(0)$ & $6(25)$ & $1(6)$ \\
\hline Increased dream activity & $9(39)$ & $4(25)$ & $6(26)$ & $2(12)$ \\
\hline Emotional indifference & $7(29)$ & $3(19)$ & $14(56)$ & $6(35)$ \\
\hline Rigidity $^{\mathrm{a}, \mathrm{b}}$ & $4(17)$ & $0(0)$ & $7(29)$ & $0(0)$ \\
\hline Hypokinesia/akinesia & $11(46)$ & $2(12)$ & $14(54)$ & $4(23)$ \\
\hline Tremor & $7(37)$ & $4(25)$ & $13(50)$ & $4(23)$ \\
\hline Akathisia & $6(26)$ & $0(0)$ & $8(32)$ & $3(18)$ \\
\hline Accommodation disturbances & $6(26)$ & $2(12)$ & $7(32)$ & $5(29)$ \\
\hline Increased salivation ${ }^{\mathrm{b}}$ & $10(42)$ & $2(12)$ & $13(52)$ & $2(12)$ \\
\hline Reduced salivation & $9(39)$ & $4(25)$ & $2(8)$ & $1(6)$ \\
\hline Constipation & $10(42)$ & $1(6)$ & $7(27)$ & $1(6)$ \\
\hline Polyuria/polydipsia & $7(30)$ & $4(25)$ & $8(31)$ & $5(29)$ \\
\hline Orthostatic dizziness & $3(13)$ & $2(12)$ & $5(21)$ & $1(6)$ \\
\hline Palpitations/tachycardia & $11(46)$ & $1(12)$ & $8(35)$ & $1(6)$ \\
\hline Increased tendency to sweat & $8(33)$ & $1(6)$ & $7(28)$ & $5(29)$ \\
\hline Weight gain & $13(72)$ & $8(50)$ & $20(91)$ & $15(88)$ \\
\hline Amenorrhea & $1(20)$ & $0(0)$ & $4(50)$ & $0(0)$ \\
\hline Increased sexual desire & $1(6)$ & $0(0)$ & $5(28)$ & $2(14)$ \\
\hline Dry vagina & $0(0)$ & $0(0)$ & $2(22)$ & $0(0)$ \\
\hline Tension headache & $6(25)$ & $3(19)$ & $6(24)$ & $5(29)$ \\
\hline
\end{tabular}

Only those with at least $20 \%$ prevalence at some point during the study are shown in the table

${ }^{a}$ Mann-Whitney $U$ test for independent samples; significant differences when $P<0.05$

${ }^{b}$ Wilcoxon test for non-independent samples; significant differences when $P<0.05$ those patients on olanzapine. Given the lack of differences in the different symptom domains between different antipsychotics in previous studies with much larger samples (CATIE [23], EUFEST [17], CUtLASS [16]), these findings may be more likely constitute a Type II error due to small sample size than a true difference reflecting a different pharmacological profile for the two drugs.

Results are comparable to previous reports showing efficacy of SGAs in pediatric populations with psychotic symptoms. In a previous 8-week doubleblind, randomized, controlled trial in 50 children and adolescents with psychotic symptoms, comparing risperidone, olanzapine, and haloperidol, there was no difference in efficacy among the drugs, with all three antipsychotics providing a significant reduction in psychotic symptoms [38]. More recently, a 12-week open-label, randomized study comparing risperidone and olanzapine efficacy in 25 child-onset schizophrenia patients reported that both drugs provided a similar significant reduction in psychotic symptoms [28]. In an 8-week open label study in 16 adolescent patients with schizophrenia, schizophreniform, or schizoaffective disorders, olanzapine significantly decreased PANSS scores [9]. Further studies are needed to elucidate whether different antipsychotics have distinct efficacy profiles for different symptom domains, and more especially, different safety and side effect profile.

It is noteworthy that a high prevalence of side effects was found in this adolescent sample. Despite the lack of significant differences between the two treatments with respect to the presence of side effects as measured by the UKU (with the exception of rigidity and diminished sexual desire), there were many other symptoms present in more than $20 \%$ of patients
Fig. 4 Change in weight over time by treatment group

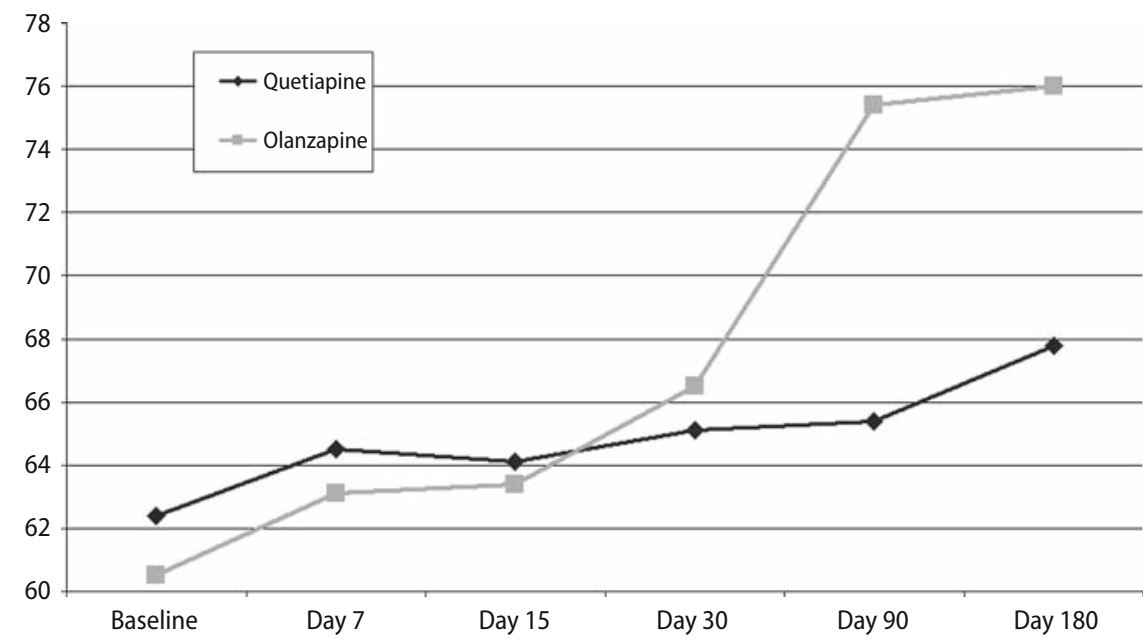


throughout the study. More than $70 \%$ of patients in both groups experienced somnolence at some point during the study and, more importantly, $69 \%$ of patients on quetiapine and $71 \%$ of patients on olanzapine experienced somnolence after 6 months of treatment. In addition, $37 \%$ of patients on quetiapine and $56 \%$ of patients on olanzapine experienced lack of concentration. These are symptoms with important daily living implications in school-age patients that should be taken in consideration when prescribing antipsychotics [1]. Clearly, more data on safety and tolerability of antipsychotics is needed in this population.

Most of the patients in this study experienced substantial weight gain. These data are clinically important for many reasons. A weight gain greater than $15 \mathrm{~kg}$ in 6 months changes the body's physical appearance at an age of great emotional turmoil. This may be specifically important in terms of treatment adherence in adolescents who worry with their physical appearance [1]. We did not find any differences between the two drugs in terms of drug discontinuation, but this could be due to the short follow-up or the clinical trial setting. Also noteworthy is the increased risk of chronic health problems associated with obesity such as diabetes, hypertension, and cardiovascular morbidity. These increases in weight are similar to those reported in first episode studies in adults on quetiapine [10, 20]. For olanzapine, we have been able to locate only studies assessing adult first episode patients for 12 weeks with $6-7.3 \mathrm{~kg}$ weight gain $[24,34]$, and up to 4 months with $7.7 \mathrm{~kg}$ weight gain [34]. Weight gain and metabolic changes have been described in this population [4, 5]. However, the weight gain in the present study is greater than that seen in more chronic pediatric patients $[9,29,37,38]$ that may have already gained weight due to antipsychotic treatment prior to study entry. Therefore, first episode psychosis patients may be a population at greater risk for this side effect, regardless of the age. This study also points to the need to assess weight gain in studies with longer follow-up periods, as this side effect does not seem to plateau after the first 6 months of treatment. Weight should be routinely measured quantitatively, since scales such as the UKU that measures only if weight gain is present or absent, miss significant differences between drugs that are clinically meaningful, as was the case in this study (Table 5).

Our results relative to free-thyroid hormone (FT4) reduction are in the line with previous reports in adult [3] and adolescent populations [10, 26, 27, 36] using similar antipsychotic doses and treatment times. Treatment with quetiapine was related to a significant decrease in FT4. Kelly and Conley argue that this effect may be secondary to competitive metabolism of thy- roid hormones and quetiapine by UDP-glucuronosyltransferase [27]. In our study, FT4 levels were within normal limits both at baseline and the 6-month assessment. Therefore, such a decrease did not have clinical implications. Further studies are needed to evaluate FT4 changes with long-term treatment.

We also found that total cholesterol levels increased significantly in patients receiving olanzapine and quetiapine. HDL cholesterol increased only in the group treated with quetiapine. Thus, the increase in total cholesterol in patients treated with olanzapine seems to be driven by a non-significant increase in LDL cholesterol. Olanzapine was reported to be related to an increase in total cholesterol in a study in five adolescents [13], although findings on the effects of olanzapine, risperidone, and quetiapine on cholesterol levels among adolescents are not conclusive $[7,10,20,38]$.

Regarding concomitant medications, patients on olanzapine experienced dystonia and required anticholinergics in a higher proportion than patients on quetiapine, although this difference was not significant. This may indicate a higher susceptibility to extrapyramidal symptoms with olanzapine as compared to quetiapine in this population. In a previous study on SGA tolerability in a pediatric population, we reported that patients treated mostly with SGAs over a one-year showed more dyskinetic movements than patients treated for less than 1 month [22]. Maturation of the dopamine system during childhood and adolescence may affect susceptibility to motor side effects differently, depending on age. Therefore, subgroups should be stratified by age when assessing dopamine-related side effects in young people exposed to SGAs.

There are several methodological limitations to this study. Firstly, we used an open-label instead of a double-blind design, which can change the expectations of patients and their caregivers, as well as therapists, even when medication is assigned randomly, thus influencing the outcome of treatment. Secondly, the small sample size of our groups may limit the study's ability to detect moderate to small differences between treatments that may be clinically significant (Type II error). In addition, it makes it difficult to do any sort of subgroup analyses, for instance between different diagnoses or age subgroups. Thirdly, a variety of concomitant medications was used. Although there were no significant differences between any particular class of adjunctive medication used in the two groups, it is theoretically possible that both the efficacy and side effects observed in this study were due to or modulated by the adjunctive medication rather than the antipsychotic drug. Fourthly, although similar completion rates were observed for both the quetiapine sample $(66.7 \%)$ and the 
olanzapine sample $(61.5 \%)$, we observed high dropout rates in both treatment arms, which may limit the generalizability of our results. However, the literature reveals 6-month studies with higher attrition rates. In a study comparing quetiapine $300,600 \mathrm{mg}$, and haloperidol, drop-out rates increased to 58,50 , and $35 \%$, respectively, before week 24 [40]. Furthermore, in another 6-month study, only $44 \%$ of the entire sample (total $n=12$ ) completed the entire protocol [33]. Finally, we used a heterogeneous sample of diagnoses. Differential diagnosis of psychotic disorders is very difficult in a pediatric population due to the atypicality and non-specificity of symptoms in psychotic episodes at this age (e.g., noncongruent delusions or hallucinations in a first episode bipolar patient) and the lack of longitudinal information about the disease course. In addition, antipsychotics have no proven disease specific efficacy or safety profile and are commonly used in all the diagnoses included in this sample. The heterogeneity of this sample should be taken into account when assessing the generalizability of the study. Diagnostic differences may also influence the use of or the response to concomitant medications.

In summary, patients in both treatment groups had a significant reduction in most clinical measurements. Side effects were common with the two drugs. The increase in weight experienced by patients treated with olanzapine during the 6 months of the study does not seem to be counterbalanced by better efficacy and, therefore, olanzapine should not be a first choice drug for this population.

Acknowledgments This work was supported by Supported by Investigator Initiated Study (D1441C00007) funded by AstraZeneca, Fundación Alicia Koplowitz, and Instituto de Salud Carlos III, Centro de Investigación Biomédica en Red de Salud Mental, CIBERSAM.

\section{References}

1. Arango C, Parellada M, Moreno DM (2004) Clinical effectiveness of new generation antipsychotics in adolescent patients. Eur Neuropsychopharmacol 14:S471-S479

2. Barnes TR (2003) The Barnes Akathisia rating scale-revisited. J Psychopharmacol 17:365-370

3. Conley RR, Kelly DL (2005) Secondgeneration antipsychotics for schizophrenia: a review of clinical pharmacology and medication-associated side effects. Isr J Psychiatry Relat Sci 42:5160

4. Correll CU, Malhotra AK (2004) Pharmacogenetics of antipsychotic-induced weight gain. Psychopharmacology (Berl) 174:477-489

5. Correll CU, Penzner JB, Parikh UH, Mughal T, Javed T, Carbon M, Malhotra AK (2006) Recognizing and monitoring adverse events of secondgeneration antipsychotics in children and adolescents. Child Adolesc Psychiatr Clin N Am 15:177-206

6. Charach A, Volpe T, Boydell KM, Gearing RE (2008) A theoretical approach to medication adherence for children and youth with psychiatric disorders. Harv Rev Psychiatry 16:126135

7. Fedorowicz VJ, Fombonne E (2005) Metabolic side effects of atypical antipsychotics in children: a literature review. J Psychopharmacol 19:533-550

8. Findling RL (2005) Update on the treatment of bipolar disorder in children and adolescents. Eur Psychiatry 20:87-91
9. Findling RL, McNamara NK, Youngstrom EA, Branicky LA, Demeter CA, Schulz SC (2003) A prospective, openlabel trial of olanzapine in adolescents with schizophrenia. J Am Acad Child Adolesc Psychiatry. 42:170-175

10. Fraguas D, Merchan-Naranjo J, Laita $P$, Parellada M, Moreno D, Ruiz-Sancho A, Cifuentes A, Giraldez M, Arango C (2008) Metabolic and hormonal side effects in children and adolescents treated with second-generation antipsychotics. J Clin Psychiatry 69:11661175

11. Goodman R (1999) The extended version of the strengths and difficulties questionnaire as a guide to child psychiatric caseness and consequent burden. J Child Psychol Psychiatry 40:791799

12. Goodman R (1997) The strengths and difficulties questionnaire: a research note. J Child Psychol Psychiatry 38:581-586

13. Gothelf D, Apter A, Reidman J, BrandGothelf A, Bloch Y, Gal G, Kikinzon L, Tyano S, Weizman R, Ratzoni G (2003) Olanzapine, risperidone and haloperidol in the treatment of adolescent patients with schizophrenia. J Neural Transm 110:545-560

14. Guy W (1976) Clinical Global Impression. ECDEU Assessment Manual for Psychopharmacology revised. National Institute of Mental Health, Rockville

15. Hamilton M (1967) Development of a rating scale for primary depressive illness. Br J Soc Clin Psychol 6:278-296
16. Jones PB, Barnes TR, Davies L, Dunn G, Lloyd H, Hayhurst KP, Murray RM, Markwick A, Lewis SW (2006) Randomized controlled trial of the effect on quality of life of second- vs first-generation antipsychotic drugs in schizophrenia: cost utility of the latest antipsychotic drugs in schizophrenia study (CUtLASS 1). Arch Gen Psychiatry 63:1079-1087

17. Kahn RS, Fleischhacker WW, Boter H, Davidson M, Vergouwe Y, Keet IP, Gheorghe MD, Rybakowski JK, Galderisi $S$, Libiger J, Hummer $M$, Dollfus $S$, Lopez-Ibor JJ, Hranov LG, Gaebel W, Peuskens J, Lindefors N, RiecherRossler A, Grobbee DE (2008) Effectiveness of antipsychotic drugs in firstepisode schizophrenia and schizophreniform disorder: an open randomised clinical trial. Lancet 371:10851097

18. Kay SR, Opler LA, Lindenmayer JP (1989) The positive and negative syndrome scale (PANSS): rationale and standardisation. Br J Psychiatry Suppl, pp 59-67

19. Keefe RS, Sweeney JA, Gu H, Hamer RM, Perkins DO, McEvoy JP, Lieberman JA (2007) Effects of olanzapine, quetiapine, and risperidone on neurocognitive function in early psychosis: a randomized, double-blind 52-week comparison. Am J Psychiatry 164:1061-1071 
20. Kopala LC, Good KP, Milliken H, Buiteman C, Woodley H, Rui Q, Whitehorn D, Love L, Balshaw R, Kiss I, Honer WG (2006) Treatment of a first episode of psychotic illness with quetiapine: an analysis of 2 year outcomes. Schizophr Res 81:29-39

21. Kumra S, Frazier JA, Jacobsen LK, McKenna K, Gordon CT, Lenane MC, Hamburger SD, Smith AK, Albus KE, Alaghband-Rad J, Rapoport JL (1996) Childhood-onset schizophrenia. A double-blind clozapine-haloperidol comparison. Arch Gen Psychiatry 53:1090-1097

22. Laita P, Cifuentes A, Doll A, Llorente C, Cortes I, Parellada M, Moreno D, RuizSancho A, Graell M, Arango C (2007) Antipsychotic-related abnormal involuntary movements and metabolic and endocrine side effects in children and adolescents. J Child Adolesc Psychopharmacol 17:487-502

23. Lieberman JA, Stroup TS, McEvoy JP, Swartz MS, Rosenheck RA, Perkins DO, Keefe RS, Davis SM, Davis CE, Lebowitz BD, Severe J, Hsiao JK (2005) Effectiveness of antipsychotic drugs in patients with chronic schizophrenia. $\mathrm{N}$ Engl J Med 353:1209-1223

24. Lieberman JA, Tollefson G, Tohen M, Green AI, Gur RE, Kahn R, McEvoy J, Perkins D, Sharma T, Zipursky R, Wei H, Hamer RM (2003) Comparative efficacy and safety of atypical and conventional antipsychotic drugs in first-episode psychosis: a randomized, double-blind trial of olanzapine versus haloperidol. Am J Psychiatry 160:13961404

25. Lingjaerde O, Ahlfors UG, Bech P, Dencker SJ, Elgen K (1987) The UKU side effect rating scale. A new comprehensive rating scale for psychotropic drugs and a cross-sectional study of side effects in neuroleptic-treated patients. Acta Psychiatr Scand Suppl 334:1-100
26. McConville B, Carrero L, Sweitzer D, Potter L, Chaney R, Foster K, Sorter M, Friedman L, Browne K (2003) Longterm safety, tolerability, and clinical efficacy of quetiapine in adolescents: an open-label extension trial. J Child Adolesc Psychopharmacol 13:75-82

27. McConville BJ, Arvanitis LA, Thyrum PT, Yeh C, Wilkinson LA, Chaney RO, Foster KD, Sorter MT, Friedman LM, Brown KL, Heubi JE (2000) Pharmacokinetics, tolerability, and clinical effectiveness of quetiapine fumarate: an open-label trial in adolescents with psychotic disorders. J Clin Psychiatry 61:252-260

28. Mozes T, Ebert T, Michal SE, Spivak B, Weizman A (2006) An Open-label randomized comparsion of olanzapine versus risperidone in the treatment of childhood-onset schizophrenia. J Child Adolesc Psychopharmacol 16:393-403

29. Mozes T, Toren P, Chernauzan N, Mester R, Yoran-Hegesh R, Blumensohn R, Weizman A (1994) Clozapine treatment in very early onset schizophrenia. J Am Acad Child Adolesc Psychiatry 33:65-70

30. Naber D, Karow A, Lambert M (2005) Subjective well-being under the neuroleptic treatment and its relevance for compliance. Acta Psychiatr Scand Suppl, pp 29-34

31. Naber D, Moritz S, Lambert M, Pajonk FG, Holzbach R, Mass R, Andresen B (2001) Improvement of schizophrenic patients' subjective well-being under atypical antipsychotic drugs. Schizophr Res 50:79-88

32. Olfson M, Blanco C, Liu L, Moreno C, Laje G (2006) National trends in the outpatient treatment of children and adolescents with antipsychotic drugs. Arch Gen Psychiatry 63:679-685

33. Purdon SE, Snaterse M (1998) Selective serotonin reuptake inhibitor modulation of clozapine effects on cognition in schizophrenia. Can J Psychiatry 43:8485
34. Sengupta SM, Klink R, Stip E, Baptista T, Malla A, Joober R (2005) Weight gain and lipid metabolic abnormalities induced by olanzapine in first-episode, drug-naive patients with psychotic disorders. Schizophr Res 80:131-133

35. Shaffer D, Gould MS, Brasic J, Ambrosini P, Fisher P, Bird H, Aluwahlia S (1983) A children's global assessment scale (CGAS). Arch Gen Psychiatry 40:1228-1231

36. Shaw JA, Lewis JE, Pascal S, Sharma RK, Rodriguez RA, Guillen R, PupoGuillen M (2001) A study of quetiapine: efficacy and tolerability in psychotic adolescents. J Child Adolesc Psychopharmacol 11:415-424

37. Shaw P, Sporn A, Gogtay N, Overman GP, Greenstein D, Gochman P, Tossell JW, Lenane M, Rapoport JL (2006) Childhood-onset schizophrenia: a double-blind, randomized clozapineolanzapine comparison. Arch Gen Psychiatry 63:721-730

38. Sikich L, Hamer RM, Bashford RA, Sheitman BB, Lieberman JA (2004) A pilot study of risperidone, olanzapine, and haloperidol in psychotic youth: a double-blind, randomized, 8-week trial. Neuropsychopharmacology 29:133-145

39. Simpson GM, Angus JW (1970) A rating scale for extrapyramidal side effects. Acta Psychiatr Scand Suppl 212:11-19

40. Velligan DI, Newcomer J, Pultz J, Csernansky J, Hoff AL, Mahurin R, Miller AL (2002) Does cognitive function improve with quetiapine in comparison to haloperidol? Schizophr Res 53:239-248

41. Voruganti LP, Awad AG, Parker G, Forrest C, Usmani Y, Fernando ML, Senthilal S (2007) Cognition, functioning and quality of life in schizophrenia treatment: results of a one-year randomized controlled trial of olanzapine and quetiapine. Schizophr Res 96:146155

42. Young RC, Biggs JT, Ziegler VE, Meyer DA (1978) A rating scale for mania: reliability, validity and sensitivity. $\mathrm{Br} \mathrm{J}$ Psychiatry 133:429-435 